\title{
Carotid Baroreflex Activation: Past, Present, and Future
}

\author{
Ingrid J. M. Scheffers • Abraham A. Kroon • \\ Peter W. de Leeuw
}

Published online: 10 February 2010

(C) The Author(s) 2010. This article is published with open access at Springerlink.com

\begin{abstract}
Electrical activation of the carotid baroreceptor system is an attractive therapy for the treatment of resistant hypertension. In the past, several attempts were made to directly activate the baroreceptor system in humans, but the method had to be restricted to a few selected patients. Adverse effects, the need for better electrical devices and better surgical techniques, and the lack of knowledge about long-term effects has greatly hampered developments in this area for many years. Recently, a new and promising device was evaluated in a multicenter feasibility trial, which showed a clinically and statistically significant reduction in office systolic blood pressure $(>20 \mathrm{~mm} \mathrm{Hg})$. This reduction could be sustained for at least 2 years with an acceptable safety profile. In the future, this new device may stimulate further application of electrical activation of the carotid baroreflex in treatment-resistant hypertension.
\end{abstract}

Keywords Baroreceptor system - Electrical activation · Hypertension

\section{Introduction}

Lowering blood pressure to values below 140/90 $\mathrm{mm} \mathrm{Hg}$ is of great value for patients with essential hypertension. For those with comorbidities such as diabetes mellitus or renal impairment, the target should even be lower, but with the available antihypertensive drugs, many patients either cannot obtain full control of their hypertension with

I. J. M. Scheffers $\cdot$ A. A. Kroon · P. W. de Leeuw $(\bowtie)$

Department of Internal Medicine,

Maastricht University Medical Centre,

PO Box 5800, 6202 AZ Maastricht, The Netherlands

e-mail: p.deleeuw@intmed.unimaas.nl medical therapy alone or cannot tolerate the adverse effects of the treatment. Drug-resistant hypertension thus remains a significant clinical problem in a number of patients, who could benefit from alternative treatments such as electrical activation of the carotid baroreceptors.

This review summarizes early observations on the baroreceptor system and past experiments on electrical activation of the carotid baroreceptor system. These observations and experiments have contributed to our current understanding of the baroreceptor system in the regulation of blood pressure. It also discusses recent experiences with a newly developed baropacing device, which is still under investigation, and the future role of carotid baroreflex activation therapy in the treatment of hypertension and other diseases.

A comprehensive search of databases (PubMed, MEDLINE, and OLDMEDLINE) was performed, covering the years 1950 to 2009. The keywords carotid sinus, baroreflex, electrical activation, hypertension, and angina pectoris were used in the literature search. Reference lists in found articles were also reviewed for other relevant articles. Articles in languages other than English, French, German, or Dutch were excluded.

\section{Early Observations on the Baroreceptor System}

In 1836, Cooper [1] was among the first to describe the role of the baroreceptor system in the regulation of blood pressure. More than 85 years later, Hering [2] demonstrated in dogs that electrical stimulation of the carotid sinus nerve induced both bradycardia and hypotension, and that transection of this nerve reversed these changes. He was also able to show that bilateral transection of the carotid sinus nerve resulted in systemic hypertension. Similar results were reported later by Korner [3], who observed in 
rabbits an increase in blood pressure (as well as in cardiac output and heart rate) after bilateral transection of the carotid nerves. Later on, several other investigators noted that blood pressure became very unstable after denervation of the baroreceptors. Taken together, their data suggested that the primary function of the baroreceptor system is to stabilize blood pressure and to prevent large, short-term pressure fluctuations. Accordingly, Cowley, Liard, and Guyton [4] proposed that the baroreflex system is not important for the long-term regulation of blood pressure and that previous data on the development of hypertension after carotid sinus nerve denervation in animals had been highly exaggerated, presumably as a result of methodologic errors.

Nonetheless, interest in the role of the baroreceptor system in hypertension has continued, and various methods have been developed to challenge the system. These methods include blocking the carotid sinus area using procaine or lidocaine and stimulating it using epinephrine. Other researchers have stimulated the carotid sinus area using the neck cuff technique. With this device, it is possible to create a negative pressure around the neck, resulting in increased transmural pressure in the carotid arteries. Such stimulation of the baroreceptor elicits significant decreases in blood pressure, heart rate, and cardiac output in both hypertensive and normotensive subjects.

Kubicek and colleagues [5] wondered why the baroreceptor system fails to restore blood pressure to normal levels in hypertensive patients. Using chronic splanchnic nerve stimulation, they discovered the mechanism of resetting of the baroreceptor system. Their data indicated that it is possible for the baroreceptors and/or the central nervous system pathways to adapt to chronically elevated arterial blood pressure. Subsequently, electroneurographic studies showed fewer impulses along the carotid sinus nerve in dogs with renal hypertension than in normotensive dogs [6]. These results implied that once the reflex was reset, the baroreceptor system would act to maintain the blood pressure at the elevated level.

Bristow and colleagues [7] showed that the baroreceptor system in patients with hypertension not only is reset, but also is less sensitive. They assessed baroreceptor sensitivity based on the relationship between changes in systolic blood pressure and changes in $\mathrm{R}-\mathrm{R}$ intervals after intravenous bolus injections of angiotensin II. Subsequently, several research groups confirmed that the baroreceptor system is less sensitive under conditions of elevated pressure. AngellJames and George [8] concluded that, at least in rabbits, the reduction in baroreceptor sensitivity is related more closely to the duration of hypertension than to its severity. All these data support the notion that the baroreflex system more or less passively follows the development of hypertension and that activation of the system is unlikely to produce sustained reductions in blood pressure.

\section{Early Experiments on Carotid Baroreflex Activation}

\section{Animal Experiments}

Despite the foregoing, there has been ongoing interest in devices to stimulate the baroreceptor system. Pioneering work was done by Bilgutay and Lillehei [9], who designed a compact, implantable device with two flat, discoid, stainless steel electrodes that were attached directly to the baroreceptor area and sutured in the wall of the carotid arteries. The unit was triggered intermittently by $\mathrm{R}$ waves picked up from the heart by an electrode. These investigators reported on the results of their experiments in four groups of dogs: normotensive, acute neurogenic hypertensive, renal hypertensive, and arteriosclerotic. Bilateral electrical stimulation of the baroreceptor for $2 \mathrm{~h}$ caused a drop in blood pressure in all dogs, but the best results were seen in the hypertensive dogs, with decreases ranging from 28 to $100 \mathrm{~mm} \mathrm{Hg}$ systolic and from 12 to $75 \mathrm{~mm} \mathrm{Hg}$ diastolic. Griffith and Schwartz [10] also designed an implantable device with a bipolar electrode that was attached directly to the carotid sinus nerve. They showed that unilateral electrical stimulation in normotensive and renal hypertensive dogs (with or without sectioning of the contralateral carotid sinus nerve) reduced blood pressure in all animals. After the stimulation was discontinued, blood pressure quickly returned to baseline levels. A few years later, Neistadt and Schwartz [11] reported similar results in 14 adult dogs with experimentally induced hypertension. They applied an implantable carotid sinus nerve stimulator with two electrodes and an external rechargeable transmitter. On the day of implantation, a 36\% decrease of mean arterial pressure was measured. During the first month, three dogs died and five extracted their stimulator, so only six dogs were evaluated at 1 month. The average decrease in mean arterial pressure with carotid nerve stimulation was $30 \%$. After 2 months, three dogs could be evaluated; at that time, the average decrease in pressure was $23 \%$.

In 1969, Agishi and colleagues [12] reported on their experiments with carotid sinus nerve stimulation in mongrel dogs. Direct stimulation caused a drop in blood pressure in all normotensive and hypertensive dogs. Chronic stimulation was applied in eight hypertensive dogs and all responded well. Other researchers have also shown a reduction in blood pressure in animals subjected to carotid sinus nerve stimulation. From these experiments, one can conclude that stimulation of the carotid baroreceptor or carotid sinus nerve can, indeed, lower blood pressure, at least in experimental animals. 


\section{Human Experiments}

Carlsten and colleagues [13] were the first to report on the effects of brief episodes of direct carotid sinus stimulation in humans. They studied five patients with neck cancer, in whom the cancer process made a dissection of the carotid sinus region necessary. Their findings were identical to those obtained in the animal experiments. Electrical stimulation of the carotid sinus nerve caused a typical response, with a prompt fall in mean blood pressure, pulse amplitude, and heart rate. In 1966, Bilgutay and Lillehei [14] reported on the results of the first two patients who were treated with an electronic implantable device for up to 12 months. These patients experienced an immediate and significant reduction in blood pressure of 70/35 and 100/ $40 \mathrm{~mm} \mathrm{Hg}$. In the first patient, blood pressure remained at the lower level, but in the second patient, the pressure tended to return towards baseline levels. At about the same time, Schwartz and colleagues [15] published their results on chronic electrical stimulation of the carotid sinus nerve in 11 humans. Eight patients, who had been subjected to carotid sinus nerve stimulation for periods varying between 5 months and $2 \frac{1}{2}$ years, were treated successfully, with a sustained reduction in blood pressure of 30 to $100 \mathrm{~mm} \mathrm{Hg}$ systolic and 24 to $80 \mathrm{~mm} \mathrm{Hg}$ diastolic. Two patients responded only minimally and one died of renal failure 2 months postoperatively.

Since these initial observations, several investigators have applied electrical activation of the baroreceptor system in patients with resistant hypertension and those with severe angina pectoris. Altogether, 64 cases of chronic electrical activation of the baroreceptor system in the treatment of hypertension have been reported (Table 1) [14-35]. In 44 of these, significant reductions in blood pressure were shown, ranging from 15 to $130 \mathrm{~mm} \mathrm{Hg}$ systolic and from 10 to $80 \mathrm{~mm} \mathrm{Hg}$ diastolic, with follow-up periods ranging from 1 to 37 months. In one study with three patients, the followup period was not specified [20]. Of these 44 responsive patients, 8 no longer received any antihypertensive drugs $[15,28]$. Two other patients had a minimal response [15] and two patients had no response at all [31]. Most of the remaining 16 patients had a favorable response initially, but they died, stopped treatment, or were lost to follow-up within 3 months after implantation: two died because of stroke, three because of renal failure, two because of pulmonary embolism, and one because of hyperkalemia and ventricular arrhythmia [14, 15, 27-29, 35]. For two patients, the cause of death was not identified [24, 29]. Three patients stopped treatment because of serious side effects, one patient required removal of the stimulator, and two patients were lost to follow-up [15, 29, 32].

In 1967, Braunwald and colleagues [36] first reported the relief of angina pectoris by electrical activation of the baroreceptor system in humans. Because the oxygen requirements of the heart are directly related to heart rate, the inotropic state of the myocardium, and intraventricular pressure, these authors felt that if these factors could be reduced, the oxygen demands of the heart would also be diminished, resulting in a decrease in the incapacitating symptoms of angina. In total, 135 cases of chronic electrical stimulation in the treatment of angina pectoris have been reported in the literature, with significant relief of pain

Table 1 Early publications on electrical activation of the carotid baroreceptor system in treating hypertension

\begin{tabular}{|c|c|c|c|c|c|}
\hline Year & Study & Earlier publications on same patients & Patients, $n$ & Follow-up, mo & Blood pressure results \\
\hline 1966 & Bilgutay \& Lillehei [14] & - & 2 & 12 & 1 , significant $\downarrow ; 1$, lost to follow-up \\
\hline 1967 & Schwartz et al. [15] & - & 11 & $5-30$ & $\begin{array}{l}\text { 6, significant } \downarrow ; 2 \text {, minimal response; } \\
3 \text {, lost to follow-up }\end{array}$ \\
\hline 1968 & Khatri \& Cohn [20] & - & 3 & Unknown & 3 , significant $\downarrow$ \\
\hline 1969 & Parsonnet et al. [21] & Rothfeld et al. [23] & 1 & 3 & 1 , significant $\downarrow$ \\
\hline 1969 & Warembourg et al. [24] & - & 3 & $5-8$ & 2, significant $\downarrow ; 1$, lost to follow-up \\
\hline 1970 & Kaufmann et al. [26] & - & 1 & 1 & 1 , significant $\downarrow$ \\
\hline 1970 & Torresani et al. [27] & Jouve [19]; Torresani et al. $[17,18]$ & 3 & $12-15$ & 2 , significant $\downarrow ; 1$, lost to follow-up \\
\hline 1972 & Brest et al. [28] & Brest [25] & 8 & $7-16$ & 6 , significant $\downarrow ; 2$, lost to follow-up \\
\hline 1972 & Tuckman et al. [29] & Reich [22]; Tuckman et al. [16] & 12 & $4-37$ & 7 , significant $\downarrow ; 5$, lost to follow-up \\
\hline 1973 & Both et al. [30] & - & 1 & 6 & 1 , significant $\downarrow$ \\
\hline 1973 & Ernst et al. [31] & - & 5 & $5-10$ & 3, significant $\downarrow ; 2$, no response \\
\hline 1973 & Wagner et al. [32] & - & 5 & $2-18$ & 4 , significant $\downarrow ; 1$, lost to follow-up \\
\hline 1975 & Solti et al. [33] & - & 1 & 13 & 1 , significant $\downarrow$ \\
\hline 1977 & Myers [34] & - & 1 & 96 & 1 , significant $\downarrow$ \\
\hline 1980 & Saadjian et al. [35] & - & 7 & $10-36$ & 5 , significant $\downarrow ; 2$, lost to follow-up \\
\hline
\end{tabular}

$\downarrow$-decrease. 
shown in 114 patients, with follow-up periods ranging from 1 to 132 months. Fourteen patients died; for nine of these, the cause of death (eg, bradycardia, ventricular fibrillation, heart failure, myocardial infarction, or pulmonary infarction) was related to the procedure.

\section{Problems and Side Effects}

Despite the initial positive and promising results, electrical activation of the baroreceptor system has remained restricted to a carefully selected group of patients in only a few institutions. Developments in this area probably were hampered by the simultaneous introduction of more effective and better tolerated antihypertensive drugs, but several questions also remain unanswered and several problems are unresolved. One of these is where the electrodes should be placed. In most of the humans treated, the electrodes were placed on the carotid sinus nerves, even though experiments in animals with placement of the electrodes on the carotid baroreceptors also showed good results. No advantages or disadvantages for a certain position of the electrodes were mentioned in the literature, but a nerve seems more fragile than an artery, and risks for trauma and devascularization are greater with dissection of the nerve than with dissection of the artery. Limitations of surgical techniques at that time were another problem; better techniques were necessary to limit the risks and shorten the duration of the implant procedure.

Determining the best site of stimulation is another problem. Parsonnet and colleagues [37] showed similar effects on blood pressure with bilateral nerve stimulation or unilateral stimulation of the most responsive nerve. In contrast, Schwartz and colleagues [15] demonstrated that bilateral stimulation was more effective than the summation of the pressure reduction resulting from unilateral stimulation of the two nerves. It is difficult to determine the most responsive nerve preoperatively, and differences in responsiveness could also occur as a result of surgical trauma.

Another problem is the system of stimulation. In an open-loop system, the duration, frequency, and amplitude of impulses must be fixed after testing to find out the optimal adjustments. Possible changes in the sensitivity of the baroreceptors or the effect of the stimulation are not taken into consideration because there is no feedback of the actual cardiovascular status to the stimulator. From this point of view, the introduction of a feedback loop can improve the possibilities of electrical activation of the baroreceptor system [38]. In experimental studies, where closed-loop stimulation has been compared with open-loop stimulation, all patients achieved similar hemodynamic results, but a lower intensity of stimulation was required in the closed-loop stimulation system [39].

A final problem is the long-term effect of the procedure. Much uncertainty remains regarding damage and degeneration of the sinus nerve fibers, along with nerve fatigue and resetting of the baroreceptor mechanism after a long period of electrical stimulation. In addition, little is known about long-term effects on the function of the heart and other organs. Proper investigation of chronic stimulation is important to evaluate the long-term effects of baroreceptor system stimulation.

Besides these problems, the reported side effects may have hampered developments in this area. The most obvious effect is the occurrence of pain in the mandible, teeth, external auditory canals, throat, and chest, as well as in the postauricular, posterior neck, and suboccipital regions [12, 15, 28 30, 40]. Also, adverse effects as dysphonia, dysphagia, hyperpnea, tachypnea, laryngospasm, gagging, coughing, edema around the electrodes, and hypotension have been reported [15, 22, 29, 41, 42]. These effects were caused by nonoptimal settings of the stimulator, leakage or spread of the electrical signal from the electrodes, and improper positioning of the electrodes. Improper positioning can weaken or disturb the electrical signals [15, 43]. It also can lead to stimulation of muscle fibers or motor nerves, with subsequent contraction of adjacent muscles [12, 40].

\section{Recent Experiences and Developments}

Recently, the sympathetic nervous system has moved toward the center of cardiovascular medicine, because it seems to be a key factor in the genesis of essential hypertension [44]. More and more research strongly suggests that the baroreceptors play a role in the longterm control of arterial pressure [45]. As a result, interest is growing in antihypertensive therapies with beneficial effects on hypertension-related sympathetic activation [46, 47]. In 2004, Lohmeier et al. [48] published the results of a study of prolonged activation of the baroreflex. He showed sustained hypotension in six dogs that were subjected to continuous carotid baroreceptor stimulation for 7 days. With these results and today's improved surgical techniques and microelectronics, it is time to reevaluate the possible role of electrical carotid baroreflex activation in treating patients with resistant hypertension.

The Rheos Baroreflex Hypertension Therapy System (CVRx, Inc.; Minneapolis, MN, USA) recently became available. Detailed descriptions of this device and the surgical technique used have been previously published $[49,50 \bullet \cdot$. In general, the Rheos System uses bilateral carotid artery stimulation with an open-loop system. The device is totally implantable, consisting of a pulse generator and two leads. It uses modern microelectronics and a special lead design for chronic electrical activation of the carotid sinus baroreflex to reduce blood pressure. The two leads conduct the activation energy from the pulse generator to the baroreceptors located on the left and right 
carotid arteries. A programmer system can interact with the pulse generator, making it possible to noninvasively control the delivery of the activation energy. The device has independent output circuits for the left and right leads, and four independent therapies can be programmed, to optimize the performance. Each therapy has independent control of start and stop times, ramp function, dose settings, burst settings, pulse amplitude, pulse width, pulse frequency, and therapy pathway.

In 2003, 11 normotensive patients undergoing carotid endarterectomy were enrolled in the Baroreflex Activation System Study (BRASS) [51•]. The carotid sinus baroreceptors were briefly stimulated under local or general anesthesia through 1-minute incremental intervals. This study demonstrated an average decrease in systolic blood pressure from $144 \mathrm{~mm} \mathrm{Hg}$ to $131 \mathrm{~mm} \mathrm{Hg}$, directly related to the intensity of stimulation. Chronic experimental application in humans is the next step.

A case report recently described a patient with malignant hypertension who was successfully treated with the chronic implantable Rheos System [52••]. Now, results from a multicenter feasibility study are available; participants with treatment-resistant hypertension underwent implantation of the Rheos System. This study shows an acceptable safety profile and a clinically and statistically significant reduction in office blood pressure of over $20 \mathrm{~mm} \mathrm{Hg}$ systolic after 3 months of stimulation in 37 participants. A cohort of 17 participants was observed for up to 2 years and it was found that the blood pressure reduction could be sustained.

\section{Future Perspectives}

This new device may stimulate further research into the applicability of electrical activation of the carotid baroreflex, not only for treatment-resistant hypertension but also for related cardiovascular disorders. Studies are now being undertaken to evaluate baropacing in patients with congestive heart failure. Angina pectoris may be another area where the device could be useful.

Of course, many problems still must be addressed. Apart from technical issues, these relate to the optimal use of the system. For instance, we do not know which settings will give the best results. Currently, frequency and voltage are set empirically, but there may be more dynamic ways to stimulate the baroreceptor system. We need to find out how we can best modify the settings in relation to the circadian pattern of blood pressure and heart rate. Also, it is unknown whether both carotids must be paced or whether unilateral stimulation will be effective. Beyond determining the preferred settings, another challenge is creating a closedloop feedback system. A device that can monitor blood pressure and stimulate the baroreceptor system as needed would be a major breakthrough for patients with hitherto refractory hypertension.

Disclosure No potential conflicts of interest relevant to this article were reported.

Open Access This article is distributed under the terms of the Creative Commons Attribution Noncommercial License which permits any noncommercial use, distribution, and reproduction in any medium, provided the original author(s) and source are credited.

\section{References}

Papers of particular interest, published recently, have been highlighted as:

- Of importance

-. Of major importance

1. Cooper A: Guy's Hospital Report. In Reflexogenic Areas of the Cardiovascular System. Edited by Heymans C, Neil E. London: J\&A Churchill; 1858:457.

2. Hering H: Der Karotisdruckversuch. Münch Med Wochenschr 1923, 70:1278-1290.

3. Korner PI: The effect of section of the carotid sinus and aortic nerves on the cardiac output of the rabbit. J Physiol 1965, 180:266-278.

4. Cowley AW Jr, Liard JF, Guyton AC: Role of baroreceptor reflex in daily control of arterial blood pressure and other variables in dogs. Circ Res 1973, 32:564-576.

5. Kubicek WG, Kottke FJ, Laker DJ, Visscher MB: Adaptation in the pressor-receptor reflex mechanisms in experimental neurogenic hypertension. Am J Physiol 1953, 175:380-382.

6. McCubbin JW, Green JH, Page IH: Baroceptor function in chronic renal hypertension. Circ Res 1956, 4:205-210.

7. Bristow JD, Honour AJ, Pickering GW, et al.: Diminished baroreflex sensitivity in high blood pressure. Circulation 1969, 39:48-54.

8. Angell-James JE, George MJ: Time-course of the reduction of baroreceptor sensitivity in experimental hypertensive rabbits. Clin Sci Mol Med Suppl 1976, 3:369 s-372 s.

9. Bilgutay AM, Lillehei CW: Treatment of hypertension with an implantable electronic device. JAMA 1965, 191:649-653.

10. Griffith LS, Schwartz SI: Reversal of renal hypertension by electrical stimulation of the carotid sinus nerve. Surgery 1964, 56:232-239.

11. Neistadt A, Schwartz SI: Effects of electrical stimulation of the carotid sinus nerve in reversal of experimentally induced hypertension. Surgery 1967, 61:923-931.

12. Agishi T, Temples J, Peirce EC 2nd: Electrical stimulation of the carotid sinus nerve as an experimental treatment of hypertension. $\mathrm{J}$ Surg Res 1969, 9:305-309.

13. Carlsten A, Folkow B, Grimby G, et al.: Cardiovascular effects of direct stimulation of the carotid sinus nerve in man. Acta Physiol Scand 1958, 44:138-145.

14. Bilgutay AM, Lillehei CW: Surgical treatment of hypertension with reference to baropacing. Am J Cardiol 1966, 17:663-667.

15. Schwartz SI, Griffith LS, Neistadt A, Hagfors N: Chronic carotid sinus nerve stimulation in the treatment of essential hypertension. Am J Surg 1967, 114:5-15.

16. Tuckman J, Reich T, Goodman B, et al.: Effects of radio frequency carotid sinus nerve stimulators in patients with severe hypertension [abstract]. Circulation 1966, 33(Suppl III):III-231. 
17. Torresani J, Heuillet G, Monties JR, et al.: Hypertension artérielle grave. Traitement par stimulation du nerf du sinus carotidien. Arch Mal Coeur Vaiss 1967, 60:1032-1040.

18. Torresani J, Heuillet G, Rouvier M, et al.: Stimulation électrique du sinus carotidien et régulation de la tension artérielle. Mars Med 1967, 104:303-307.

19. Jouve A: La stimulation permanente des sinus carotidiens en pathologie cardio-vasculaire. Rev Med Liege 1969, 24:593597.

20. Khatri IM, Cohn JN: Cardiac and peripheral vascular effects of carotid sinus nerve stimulation in hypertension in man. Clin Res 1968, 16:235.

21. Parsonnet V, Rothfeld EL, Raman KV, Myers GH: Electrical stimulation of the carotid sinus nerve. Surg Clin North Am 1969, 49:589-596.

22. Reich T: Implantation of carotid sinus nerve stimulator. AORN J 1969, 10:53-56.

23. Rothfeld EL, Parsonnet V, Raman KV, et al.: The effect of carotid sinus nerve stimulation on cardiovascular dynamics in man. Angiology 1969, 20:213-218.

24. Warembourg H, Soots G, Pauchant M, et al.: Le traitement de l'hypertension artérielle grave par la stimulation bilatérale du nerf du sinus carotidien. A propos de trois observations. Lille Med 1969, 14:383-392.

25. Brest AN: Carotid sinus nerve stimulation. Am J Cardiol 1970, 26:328-329.

26. Kaufmann H, Piwnica A, Larens P, et al.: Traitement d'un cas d'hypertension artérielle par implantation d'un stimulateur sinucarotidien. Presse Med 1970, 78:35-36.

27. Torresani J, Chevalier-Cholat AM, Heuillet G, et al.: Stimulation du nerf du dinus carotidien et hypertension artérielle. Acta Chir Belg 1970, 69:33-41.

28. Brest AN, Wiener L, Bachrach B: Bilateral carotid sinus nerve stimulation in the treatment of hypertension. Am J Cardiol 1972, 29:821-825.

29. Tuckman J, Lyon AF, Reich T, Jacobson JH 2nd: Evaluation of carotid sinus nerve stimulation in the treatment of hypertension. Ther Umsch 1972, 29:382-391.

30. Both A, Reidemeister JC, Hofer I, et al.: Die Behandlung der malignen hypertension mit permanenter carotissinusnervstimulation. Verh Dtsch Ges Inn Med 1973, 79:776-777.

31. Ernst CB, Hansson L, Hunyor SN, Julius S: Stimulering av sinusnerverna med implanterad baropacer vid terapiresistent hypertension. Lakartidningen 1973, 70:1166-1168.

32. Wagner J, Wilbrandt R, Kreutzberg B, Olnhoff U: Carotissinusnervenstimulation zur beeinflussung maligner hypertonien. Verh Dtsch Ges Inn Med 1973, 79:777-781.

33. Solti F, Szabo Z, Kerkovits G, et al.: Baropacing of the carotid sinus nerve for treatment of "intractable" hypertension. Z Kardiol 1975, 64:368-374.

34. Myers MG: Clonidine-induced facilitation of baroreceptor reflex. Br Med J 1977, 2(6090):802-803.

35. Saadjian A, Torresani J, Puddu PE: Clinical interest of carotid sinus nerve stimulation in man. G Ital Cardiol 1980, 10:15781582.
36. Braunwald E, Epstein SE, Glick G, et al.: Relief of angina pectoris by electrical stimulation of the carotid-sinus nerves. N Engl J Med 1967, 277:1278-1283.

37. Parsonnet V, Myers GH, Holcomb WG, Zucker IR: Radiofrequency stimulation of the carotid baroreceptors in the treatment of hypertension. Surg Forum 1966, 17:125-127.

38. Peters TK, Koralewski HE, Zerbst E: The principle of electrical carotid sinus nerve stimulation: a nerve pacemaker system for angina pectoris and hypertension therapy. Ann Biomed Eng 1980, $8: 445-458$.

39. Korsukewitz J, Wagner J, Dittberner KH, Zerbst E: Methoden zur verbesserung der elektrischen carotissinusnerven-reizung. Klin Wochenschr 1973, 51:506-510.

40. Dennison AD Jr, Lulu DJ: Carotid sinus nerve stimulation, clinical applications and case report. J Iowa Med Soc 1972, 62:478-484.

41. Yatteau RF, Hartman CW, Soule TI, Wagner GS: Laryngospasm induced by a carotid-sinus-nerve stimulator. N Engl J Med 1971, 284:709-710.

42. Zeft HJ, Ruskin J, McGowan RL, Roman L: Hypotension and carotid-sinus-nerve stimulation. N Engl J Med 1969, 281:103-104.

43. Testerman RL, Hagfors NR, Schwartz SI: Design and evaluation of nerve stimulating electrodes. Med Res Eng 1971, 10:6-11.

44. Esler M, Kaye D: Sympathetic nervous system activation in essential hypertension, cardiac failure and psychosomatic heart disease. J Cardiovasc Pharmacol 2000, 35:S1-S7.

45. Thrasher TN: Baroreceptors and the long-term control of blood pressure. Exp Physiol 2004, 89:331-335.

46. Mancia G, Grassi G: Antihypertensive treatment: past, present and future. J Hypertens Suppl 1998, 16:S1-S7.

47. Grassi G: Sympathetic deactivation as a goal of nonpharmacologic and pharmacologic antihypertensive treatment: rationale and options. Curr Hypertens Rep 2003, 5:277-280.

48. Lohmeier TE, Irwin ED, Rossing MA, et al.: Prolonged activation of the baroreflex produces sustained hypotension. Hypertension 2004, 43:306-311.

49. Scheffers IJ, Kroon AA, Tordoir JH, de Leeuw PW: Rheos Baroreflex Hypertension Therapy System to treat resistant hypertension. Expert Rev Med Devices 2008, 5:33-39.

50. • Tordoir JH, Scheffers I, Schmidli J, et al.: An implantable carotid sinus baroreflex activating system: surgical technique and short-term outcome from a multi-center feasibility trial for the treatment of resistant hypertension. Eur J Vasc Endovasc Surg 2007, 33:414-421. This article describes the technique of baropacer implantation and preliminary results.

51. - Schmidli J, Savolainen H, Eckstein F, et al.: Acute device-based blood pressure reduction: electrical activation of the carotid baroreflex in patients undergoing elective carotid surgery. Vascular 2007, 15:63-69. This article presents the first in vivo results of acute baropacing in humans using the new device.

52. •• Mohaupt MG, Schmidli J, Luft FC: Management of uncontrollable hypertension with a carotid sinus stimulation device. Hypertension 2007, 50:825-828. This article presents an interesting observation of a patient with refractory hypertension, in whom blood pressure could be lowered with the baropacer. 